\title{
REVIEW \\ LRb signals act within a distributed network of leptin-responsive neurones to mediate leptin action
}

\author{
G. M. Leinninger and M. G. Myers, Jr. \\ Division of Metabolism, Endocrinology and Diabetes, Departments of Medicine and Molecular and Integrative Physiology, University of \\ Michigan Medical School, Ann Arbor, MI, USA
}

Received I May 2007,

accepted 17 August 2007

Correspondence: M. G. Myers, Jr.,

Division of Metabolism,

Endocrinology and Diabetes,

Departments of Internal Medicine

and Molecular and Integrative

Physiology, University of Michigan

Medical School, I I 50 W. Medical

Center Dr, 5560 MSRB II, Box

0678, Ann Arbor, MI 48I09-0678,

USA.

E-mail: mgmyers@umich.edu

\begin{abstract}
The adipose tissue-derived hormone, leptin, acts via its receptor $(\mathrm{LRb})$ in the brain to regulate energy balance and neuroendocrine function. In order to understand leptin action we have explored the physiological function of LRb signalling pathways, defining important roles for signal transducer and activator of transcription-3 (STAT3) in positive signalling and for LRbTyr $_{985}$-mediated feedback inhibition in leptin signal attenuation. As the cells on which leptin acts are not homogeneous, but rather represent a broadly distributed network of neurones with divergent projections and functions, it is also crucial to consider how each of these populations responds to LRb signals to contribute to leptin action. While well-known $\mathrm{LRb}$-expressing neurones within the arcuate nucleus of the hypothalamus mediate crucial effects on satiety and energy expenditure, other populations of LRb-expressing neurones in the ventral tegmental area and elsewhere likely control the mesolimbic dopamine system. Additional populations of LRbexpressing neurones likely contribute to other aspects of neuroendocrine regulation. It will be important to define the molecular mechanisms by which leptin acts to regulate neurophysiology in each of these LRb-expressing neural populations in order to understand the totality of leptin action. Keywords dopamine, energy balance, hypothalamus, leptin, STAT3.
\end{abstract}

\section{Leptin}

The adipose tissue-derived hormone leptin is produced in proportion to fat stores. Circulating leptin communicates the level of energy reserves in the periphery to the central nervous system in order to suppress food intake and permit energy expenditure (Friedman \& Halaas 1998, Bates \& Myers 2003, Elmquist et al. 2005, Morton et al. 2006). Adequate leptin levels permit energy expenditure on the processes of reproduction and growth, and similarly regulate other elements of the endocrine and immune systems (Ahima et al. 1996, Lord et al. 1998, Bates \& Myers 2003). Conversely, lack of leptin signalling as a consequence of mutation of leptin (e.g. ob/ob mice) or the leptin receptor (LR) (e.g. $d b / d b$ mice) in rodents and humans results in increased food intake in combination with reduced energy expenditure (and thus obesity), plus neuroendocrine dysfunction (including hypothyroidism, decreased growth, infertility and decreased immune function) (Montague et al. 1997, Clement et al. 1998, Elmquist et al. 1998b, Friedman \& Halaas 1998). Many of the effects of leptin are attributable to effects in the central nervous system (CNS), particularly in the hypothalamus, a site of high LRb mRNA expression (Elmquist et al. 2005, Morton et al. 2006).

\section{Leptin receptors}

A single Lepr gene directs the production of multiple alternatively-spliced LR isoforms that are divisible into three classes: secreted, short and long (Chua et al. 1997, Tartaglia 1997). The secreted forms are either products of alternatively spliced mRNA species (e.g. murine LRe, 
which contains only the first 14 exons of Lepr) or proteolytic cleavage products of membrane-bound forms of LR. These secreted forms contain only extracellular domains that bind circulating leptin, perhaps regulating the concentration of free leptin (Ge et al. 2002).

Short form LRs (including LRa in mice) and the single long form $\mathrm{LR}$ ( $\mathrm{LRb}$ in mice) possess identical extracellular and transmembrane domains as well as the same first 29 intracellular amino acids, but diverge in sequence thereafter. Short form LRs terminate 3-11 amino acids after the splice junction for total intracellular domain lengths of 32-40 amino acids. LRb possesses an intracellular domain of approximately 300 residues and is the crucial receptor isoform for leptin action (Chua et al. 1997, Tartaglia 1997). Indeed, the originally described $d b / d b$ mice lack LRb (but not other LR forms) as a consequence of a mutation that causes mis-splicing of the LRb mRNA; these mice closely resemble $d b^{3 J} / d b^{3 J}$ mice (which are deficient in all LR isoforms) and leptin-deficient $o b / o b$ animals (Bates \& Myers 2003). The function of shortform LRs is less clear, although proposed roles include the transport of leptin across the blood-brain barrier and the production of circulating LR extracellular domain to complex with leptin.

\section{Leptin receptor signalling}

LRb belongs to the interleukin (IL)-6 receptor family of class 1 cytokine receptors, which contain an extracellular ligand-binding domain, a single transmembrane domain and a cytoplasmic signalling domain (Taga \& Kishimoto 1997, Tartaglia 1997). Like other cytokine receptors, LRb does not contain intrinsic enzymatic activity, but instead signals via a non-covalently associated tyrosine kinase of the Janus kinase (JAK) family - Jak2 in the case of LRb (Ihle \& Kerr 1995, Taniguchi 1995, Kloek et al. 2002). Leptin binding alters the conformation of the preformed LRb homodimer, enabling transphosphorylation and activation of the intracellular LRb-associated Jak2 (Devos et al. 1997, Tartaglia 1997, Couturier \& Jockers 2003). The activated Jak2 molecule then phosphorylates other tyrosine residues within the LRb/Jak2 complex to mediate downstream signalling (White et al. 1997, Banks et al. 2000, Hekerman et al. 2005).

Tyrosine kinase-dependent signalling generally proceeds via the phosphotyrosine-dependent recruitment of signalling proteins that contain specialized phosphotyrosine-binding domains [e.g. Src homology 2 (SH2) domains] (Koch et al. 1991). Each SH2 domain isoform recognizes phosphotyrosine in a specific amino acid context. Thus, while tyrosine phosphorylation acts as a molecular switch to recruit $\mathrm{SH} 2$-containing proteins, each tyrosine phosphorylation site recruits only specific $\mathrm{SH} 2$ isoforms, as $\mathrm{SH} 2$ domains recognize the surrounding amino acids as well as the phosphotyrosine residue. For instance, the $\mathrm{SH} 2$ domain of the latent transcription factor, STAT3, binds to phosphotyrosine in the context of a Y(P)XXQ motif (Songyang et al. 1993, Haan et al. 1999). Understanding signalling by the LRb/Jak2 complex thus requires defining the tyrosine phosphorylation sites on $\mathrm{LRb}$ and Jak2 and the $\mathrm{SH} 2$ proteins that they recruit. There are three conserved tyrosine residues on the intracellular domain of $\mathrm{LRb}-\mathrm{Tyr}_{985}, \mathrm{Tyr}_{1077}$ and $\mathrm{Tyr}_{1138}$ - and data from our laboratory and others suggest that all these sites are phosphorylated and contribute to downstream leptin signalling (Tartaglia 1997, White et al. 1997, Banks et al. 2000, Hekerman et al. 2005) (and our unpublished data).

There are thus four primary intracellular signalling pathways that emanate from LRb (Fig. 1) - those originating directly from Jak 2 tyrosine phosphorylation sites plus those emanating from $\mathrm{Tyr}_{985}, \mathrm{Tyr}_{1077}$ and $\mathrm{Tyr}_{1138}$ of LRb. The phosphorylation of $\mathrm{Tyr}_{985}$ creates a binding site for the $\mathrm{COOH}$-terminal $\mathrm{SH} 2$ domain of the tyrosine phosphatase, SH2-containing tyrosine phosphatase-2, aka PTPN II (SHP-2), leading to the activation of the canonical p21ras $\rightarrow$ ERK signalling pathway in cultured cells (Banks et al. 2000, Bjorbaek et al. 2001, Kloek et al. 2002).

Phosphorylation of $\mathrm{Tyr}_{1138}$ recruits STAT3 to the $\mathrm{LRb} / \mathrm{Jak} 2$ complex, resulting in the tyrosine phosphorylation and subsequent nuclear translocation of STAT3 to mediate transcriptional regulation (White et al. 1997, Banks et al. 2000). Among other genes, STAT3 mediates the transcription of the $\mathrm{SH} 2$ domain-containing feedback inhibitor, suppressor of cytokine signalling (SOCS)-3 (Bjorbaek et al. 1998, Banks et al. 2000). SOCS3 binds to $\mathrm{Tyr}_{985}$ of $\mathrm{LRb}$ to mediate inhibition of $\mathrm{LRb} \rightarrow$ STAT3 signalling (Bjorbaek et al. 2000); SOCS3 also binds to a separate site on Jak2 itself (Sasaki et al. 2000).

$\mathrm{Tyr}_{1077}$ mediates a crucial component of STAT5 phosphorylation and transcriptional regulation by leptin, although $\mathrm{Tyr}_{1138}$ also contributes to STAT5 activation (Hekerman et al. 2005, Gong et al. 2007). $\mathrm{Tyr}_{1077}$ does not regulate STAT3 signalling, although it may promote the increased phosphorylation of LRb $\mathrm{Tyr}_{985}$.

Jak2 tyrosine phosphorylation during LRb stimulation mediates some signals independently of tyrosine phosphorylation sites on LRb, at least in cultured cells (Banks et al. 2000). The individual phosphorylation sites on Jak2 are beginning to be enumerated (Feng et al. 1997, Carpino et al. 2002, Argetsinger et al. 2004, Feener et al. 2004, Kurzer et al. 2004, Matsuda et al. 2004, Funakoshi-Tago et al. 2006, IshidaTakahashi et al. 2006), but many more remain to be 


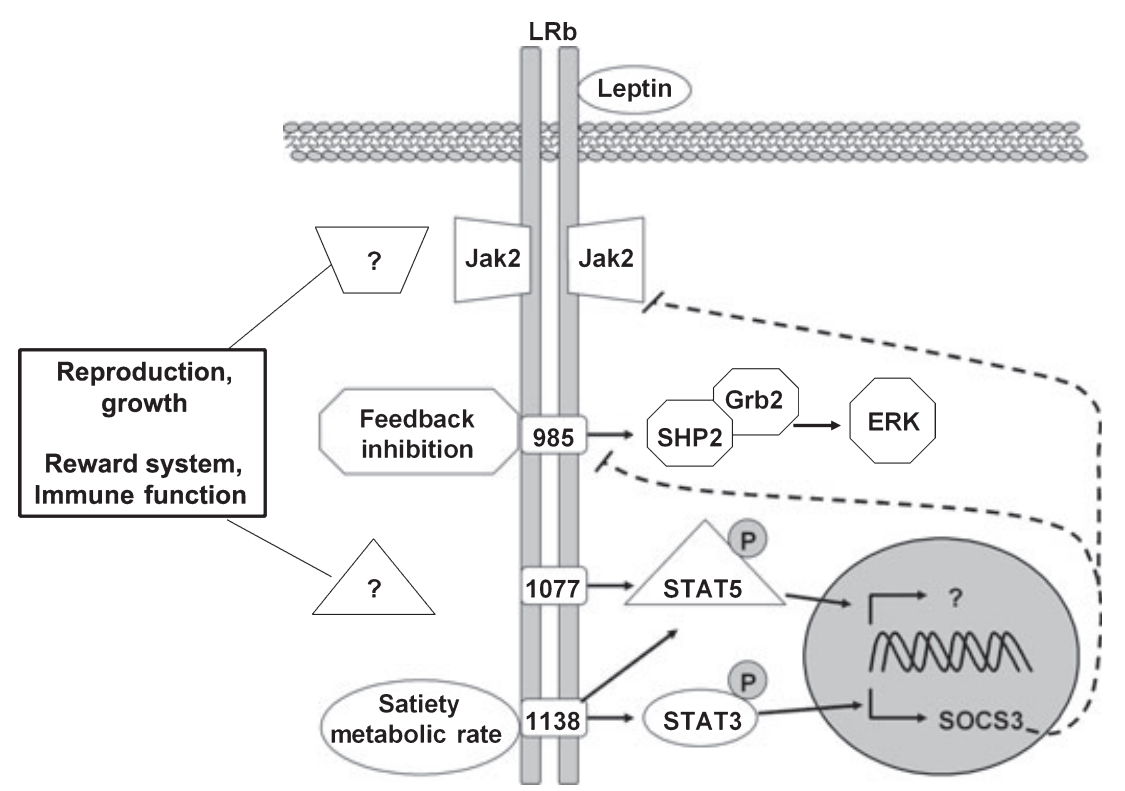

Figure I Linking LRb signalling to the regulation of mammalian physiology. Shown is a schematic of cellular LRb signalling and the roles of various signals in the regulation of physiology. Leptin binding to the extracellular domain of LRb activates the Jak2 tyrosine kinase that is constitutively associated with the intracellular domain of the receptor. This Jak2 activation results in the tyrosine phosphorylation of various sites on Jak2 and three sites on the receptor, each of which regulates different signalling pathways. LRb Tyr ${ }_{985}$ binds to SHP-2 to regulate the ERK pathway via GRB-2. $\operatorname{Tyr}_{1138}$ recruits STAT3 and contributes, along with $\mathrm{Tyr}_{1077}$, to the activation of STAT5. STAT3 and STAT5 are each latent transcription factors that translocate to the nucleus during LRb signalling to mediate transcriptional events. STAT3 prominently activates the transcription of the inhibitory SOCS3, which attenuates $\mathrm{LRb} / \mathrm{Jak} 2$ signalling by binding to $\mathrm{Tyr}_{985}$ and $\mathrm{Jak}_{2}$. $\mathrm{Tyr}_{1138}$ plays a prominent role in the regulation of satiety and metabolic rate in vivo, while $\mathrm{Tyr}_{985}$ primarily attenuates $\mathrm{LRb}$ signalling. Neither of these sites are required for reproduction or growth. The mechanisms by which LRb regulates other systems, including the mesolimbic dopamine/reward system and the immune system, also remain unclear.

identified. Unfortunately, the binding partners and signals mediated by many Jak2 phosphorylation sites remain unknown, limiting our understanding of the mechanisms by which Jak2-dependent signals are mediated. LRb stimulation regulates the phosphatidylinositol 3'-kinase (PI 3'-kinase), AMP-activated protein kinase (AMPK) and mammalian target of rapamycin (mTOR) pathways in the hypothalamus, and each of these hypothalamic pathways contributes to the regulation of feeding (Niswender et al. 2001, Minokoshi et al. 2004, Xu et al. 2005, Cota et al. 2006, Plum et al. 2006). The mechanisms by which LRb controls these pathways remain unclear, however.

\section{LRb signalling via STAT3 mediates a subset of leptin actions}

Thus far, roles for two signals mediated by LRb tyrosine phosphorylation sites have been examined in leptin action in vivo: the $\mathrm{Tyr}_{1138} \rightarrow$ STAT3 pathway and the $\mathrm{Tyr}_{985} \rightarrow$ SOCS3/SHP2 pathway (Fig. 1). We have directly addressed the contribution of the LRb-STAT3 pathway to physiology by studying homologously targeted 'knock-in' mice in which LRb is replaced by a mutant molecule $\left(\mathrm{LRb}^{\mathrm{S} 1138}\right)$ that contains a substitution mutation of $\mathrm{Tyr}_{1138}$ (the STAT3 binding site) (Bates et al. 2003). Although $\mathrm{LRb}^{\mathrm{S} 1138}$ fails to mediate activation of STAT3 during leptin signalling, this mutant regulates all other LRb signalling pathways normally. The use of the 'knock-in' approach ensures that the expression pattern and levels of $\mathrm{LRb}^{\mathrm{S} 1138}$ mirror that of wild-type LRb.

Similar to $d b / d b$ animals, mice homozygous for $\mathrm{LRb}^{\mathrm{S} 1138}$ expression $(s / s)$ display hyperphagia and decreased energy expenditure, resulting in profound obesity in the face of dramatically increased serum leptin levels. The high circulating leptin levels in $s / s$ animals not only correlate with increased adipose mass in these mice, but also indicate resistance to the energy homeostatic effects of leptin (Bates et al. 2003). Feeding is similarly high in $s / s$ and $d b / d b$ mice, and thyroid function and energy expenditure are similarly decreased in these two mouse strains (Bates et al. 2004).

However, important differences exist between the phenotypes of $s / s$ mice (missing only the LRb-STAT3 signal) and $d b / d b$ mice (devoid of all leptin signals) (Bates et al. 2003). Whereas $d b / d b$ animals are floridly 
diabetic, infertile and demonstrate decreased linear growth, $s / s$ mice exhibit greatly improved glucose tolerance compared with $d b / d b$ mice, retain relatively normal gonad function and demonstrate increased linear growth compared with wild-type animals (Bates et al. 2003, 2004, 2005, Buettner et al. 2006). The cellularity of the thymus and thrombosis in response to vessel injury (both mediated by the effects of leptin on haematopoietic-derived cells) are also enhanced in $s / s$ animals, though diminished in $\mathrm{db} / \mathrm{db}$ mice (Bodary et al. 2002, 2007, Dunn et al. 2005).

Clearly, LRb $\rightarrow$ STAT3-independent pathways mediate a number of physiological responses to leptin. It is also important to note, however, that the phenotype of the $s / s$ animals does not suggest the irrelevance of nonSTAT3 pathways in other aspects of energy balance, only that STAT3 signalling is important for the regulation of energy homeostasis. Thus, $\mathrm{Tyr}_{1138} \rightarrow$ STAT3independent signals may contribute to energy balance as well as to the myriad other effects of leptin that are normal in $s / s$ mice.

\section{LRb Tyr ${ }_{985}$ attenuates leptin action in vivo}

In order to understand the contribution of $\mathrm{LRb} \mathrm{Tyr}_{985}$ to leptin action and inhibition in vivo, we generated mice in which LRb was homologously replaced by $\mathrm{LRb}^{\mathrm{L} 985}$, which contains a non-phosphorylatable substitution mutation of $\mathrm{Tyr}_{985}$ that blocks SHP2/SOCS3 recruitment (Banks et al. 2000, Bjorbaek et al. 2000, 2001, Bjornholm et al. 2007). Mutation of $\mathrm{Tyr}_{985}$ in vivo results in reduced feeding and adiposity, and increased baseline STAT3 activation in female $l / l$ mice all in the face of low leptin levels. Coupled with the increased sensitivity of $l / l$ animals to exogenous leptin, these observations suggest that mutation of $\mathrm{Tyr}_{985}$ blocks the activation of an inhibitory $\mathrm{Tyr}_{985}$-dependent LRb signal, ultimately leading to increased leptin sensitivity in vivo. These results suggest an important role for $\mathrm{Tyr}_{985}$ in the attenuation of leptin action in vivo, consistent with results from cultured cells that suggest an important role for $\mathrm{Tyr}_{985}$ in the inhibition of LRb signalling (Carpenter et al. 1998, Li \& Friedman 1999, Bjorbaek et al. 2000).

As $\mathrm{Tyr}_{985}$ of LRb recruits both SHP-2 and SOCS3 (Carpenter et al. 1998, Li \& Friedman 1999, Bjorbaek et al. 2000), the failure of $\mathrm{LRb}^{\mathrm{L} 985}$ to recruit either of these proteins could theoretically underlie the lean, leptin-sensitive phenotype of $l / l$ mice. However, most data from cultured cells and animals support a primary role for SOCS3 in the inhibition of LRb signalling (Bjorbaek et al. 1998, 2000, 2001, Howard et al. 2004, Mori et al. 2004, Zhang et al. 2004, Dunn et al. 2005). SOCS3 mRNA expression was similar between $+/+$ and $l / l$ mice, suggesting the effect of $\mathrm{LRb} \mathrm{Tyr}_{985}$ in the attenuation of leptin action in vivo is not the result of differences in SOCS3 expression.

The phenotype of $l / l$ mice also suggests that SHP-2 may not be required for the regulation of growth or reproduction by leptin and does not mediate essential anorectic signals. This finding contrasts with the obesity and impaired neuroendocrine function in animals with deletion of SHP-2 in the forebrain (Zhang et al. 2004), suggesting that disruption of SHP-2 alters signalling by numerous factors other than leptin, and in a wide variety of neuronal populations (Feng 1999, Keilhack et al. 2005). It is possible, however, that the loss of SHP-2 recruitment by leptin in $l / l$ animals could result in a diminution of anorectic function that is obscured by the enhancement of overall LRb signalling due to the concomitant loss of inhibitory signals in $\mathrm{LRb}^{\mathrm{L} 985}$. Overall, however, LRb Tyr $1138^{-}$and $\mathrm{Tyr}_{985}$-independent signals probably contribute to the regulation of growth, reproduction, haematopoietic function and glucose homeostasis by leptin (Bates et al. 2003). The LRb $\mathrm{Tyr}_{1077} / \mathrm{STAT} 5$ pathway, or signals mediated by the LRb-associated Jak2 independently of LRb tyrosine phosphorylation (Niswender et al. 2001, Bates \& Myers 2003, Hekerman et al. 2005), are likely candidates to mediate the control of these $\mathrm{Tyr}_{985} / \mathrm{Tyr}_{1138}$-independent actions by leptin. Possible downstream pathways include the PI 3'-kinase, mTOR and AMPK pathways, although other uncharacterized signals could also participate.

\section{Leptin regulation of neural networks and neurophysiology}

$\mathrm{LRb}$ is present in several tissues, with the highest levels in neurones of several nuclei of the hypothalamus, including the arcuate (ARC), dorsomedial (DMH), ventromedial $(\mathrm{VMH})$ and ventral pre-mammillary $(\mathrm{PMv})$ nuclei and the lateral hypothalamic area (LHA) (Elmquist et al. 1998a, 2005, Baskin et al. 1999, Leshan et al. 2006, Morton et al. 2006) (Fig. 2). Other sites within the brain that have been shown to express functional LRb include the ventral tegmental area (VTA), brainstem [including the nucleus of the solitary tract (NTS)], and the periaqueductal grey matter, among others.

\section{LRb action in the ARC}

Leptin action is particularly well characterized in two populations of ARC neurones, both of which express LRb. One population synthesizes neuropeptide Y (NPY) and agouti-related peptide (AgRP) and the other synthesizes pro-opiomelanocortin (POMC) (Elmquist et al. 2005, Morton et al. 2006). POMC is processed to produce $\alpha$-melanocyte-stimulating-hormone $(\alpha-\mathrm{MSH})$ in $\mathrm{LRb} / \mathrm{POMC}$ neurones, which signals anorexia (decreased appetite) by activating the melanocortin-4 


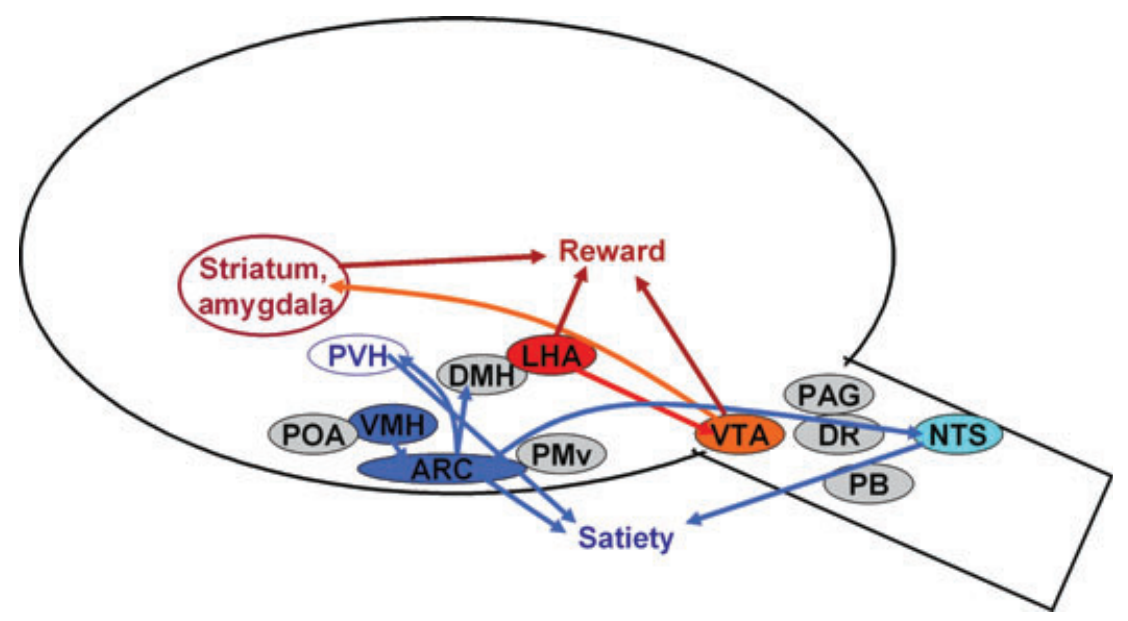

Figure 2 A distributed network of LRb-expressing leptin responsive neurones. In addition to the well-known arcuate nucleus of the hypothalamus (ARC), large populations of LRb-expressing neurones are found in a variety of other areas in the hypothalamus and brainstem (filled ovals). Regions that receive important projections from LRb neurones but that do not themselves contain large numbers of LRb neurones have white fills. Leptin action on LRb-expressing neurones in the ARC regulates neurones in the paraventricular hypothalamic nucleus $(\mathrm{PVH})$, the dorsomedial hypothalamic nucleus $(\mathrm{DMH})$ and the brainstem, including the nucleus of the solitary tract (NTS). These act, presumably along with LRb neurones within the DMH and NTS, to modulate satiety (blue circuits). The mesolimbic dopamine system (orange/red circuits) encodes incentive salience and reward; at the core of this system lie dopaminergic neurones in the ventral tegmental area (VTA) that project to the striatum and amygdala. Leptin regulates this system directly via LRb-expressing dopaminergic and non-dopaminergic neurones in the VTA, as well as via lateral hypothalamic (LHA) LRb neurones that project to the VTA to regulate dopamine production. Other areas containing less well understood LRb neurones (grey ovals) include the pre-optic area (POA), ventromedial hypothalamic nucleus (VMH), ventral premammillary nucleus (PMv), periaqeductal grey (PAG), dorsal raphe (DR) and parabrachial nucleus (PB).

receptor (MC4R) and the melanocortin-3 receptor (MC3R) (Huszar et al. 1997, Marsh et al. 1999, Butler et al. 2000, Chen et al. 2000, Ste et al. 2000, Butler \& Cone 2002). LRb stimulates the synthesis of POMC and activates/depolarizes LRb/POMC neurones (Cowley et al. 2001, Elmquist et al. 2005, Morton et al. 2006). NPY is an orexigenic (appetite-stimulating) hormone that also suppresses the central LRb-mediated growth and reproductive axes (Clark et al. 1985, Erickson et al. 1996, Elmquist et al. 2005, Morton et al. 2006). AgRP is an antagonist of $\alpha-\mathrm{MSH} / \mathrm{MC} 4 \mathrm{R}$ signalling as well as an inhibitor (inverse agonist) of endogenous MC4R activity (Ollmann et al. 1997, Elmquist et al. 2005, Morton et al. 2006). Leptin acts via LRb to inhibit NPY/AgRP neurones and suppress expression of these neuropeptides (Cowley et al. 2001, Elmquist et al. 2005, Morton et al. 2006). Thus, LRb signalling stimulates the production of anorectic neuropeptides and suppresses levels of orexigenic peptides. Conversely, a decrease or deficiency in leptin activity (e.g. during starvation and in $o b / o b$ and $d b / d b$ mice) stimulates appetite by suppressing synthesis of anorectic neuropeptides (e.g. POMC) and increasing expression of orexigenic peptides (e.g. NPY and AgRP).

We have previously examined the regulation of ARC neuropeptide expression and neuronal activity in $s / s$ and $l / l$ mice. Similar to $d b / d b$ mice, $s / s$ mice have decreased
POMC mRNA levels in the hypothalamus (Bates et al. 2003). By contrast, whereas $d b / d b$ animals display dramatic induction of hypothalamic NPY mRNA, levels of NPY message are near normal in $s / s$ animals. Furthermore, the activity of these AgRP/NPY neurones is appropriately suppressed in $s / s$, but not in $d b / d b$ animals (Munzberg et al. 2007). These data suggest that LRb-STAT3 signalling is a crucial regulator of hypothalamic melanocortin action, and that dysregulated melanocortin signalling (as opposed to alterations in NPY) may contribute to the obesity of $s / s$ animals, although STAT3 presumably mediates other leptin effects in other LRb-expressing neurones. In $l / l$ mice, levels of POMC mRNA are similar to those found in wild-type mice, although levels of NPY and AgRP are decreased in $l / l$ animals, suggesting increased LRb signalling in these animals and demonstrating that the regulation of these neuropeptides is independent of $\mathrm{Tyr}_{985}$. Hence, non-STAT3, non- $\mathrm{Tyr}_{985} \mathrm{LRb}$ signals are critical regulators of the $\mathrm{LRb} / \mathrm{NPY}$ neurone.

\section{LRb action beyond established ARC circuits}

Although we now know a great deal about the mechanisms by which the ARC NPY/AgRP and POMC neurone function, numerous questions remain regarding the magnitude of their contributions to the regulation of 
feeding in response to leptin under physiological conditions (Boston et al. 1997, Ellacott \& Cone 2006). Indeed, only $50 \%$ of ARC POMC neurones express LRb (Munzberg et al. 2003). Also, although ablation of AgRP neurones results in hypophagia and ablation of POMC or central melanocortin receptors results in severe obesity (Butler \& Cone 2002, MacNeil et al. 2002), deletion of LRb from POMC neurones or the restoration of $\mathrm{LRb}$ in the ARC of $d b / d b$ animals results in only modest alteration in body weight (Morton et al. 2003, Balthasar et al. 2004). Furthermore, although interference with LRb $\rightarrow$ STAT3 signalling in $s / s$ mice results in dramatic hyperphagia and obesity, deletion of STAT3 in POMC and NPY/AgRP neurones only modestly impacts body energy homeostasis (Bates et al. 2003, Kaelin et al. 2006, Xu et al. 2006). Thus, while melanocortins and ARC POMC and NPY/AgRP neurones generally effect powerful appetitive signals, leptin is only one factor that regulates melanocortin action, and thus these neurones may not mediate the majority of the leptin-promoted anorectic signal. The aggregate leptin signal is probably mediated in concert with many other, currently uncharacterized, populations of LRbexpressing neurones. Indeed, some data suggest the existence of additional populations of ARC LRb neurones, including those that are modified by cre recombinase activity in rat insulin II gene prometer-Cre (RIP-Cre) mice (Cui et al. 2004, Smith et al. 2007).

Arcuate LRb neurones comprise only $15-20 \%$ of the total number of LRb-expressing neurones within the CNS (Leshan et al. 2006), and other populations of $\mathrm{LRb}$ neurones, including those in the VMH, and VTA clearly mediate an important component of leptin action (Dhillon et al. 2006, Fulton et al. 2006, Hommel et al. 2006). Thus, unlike insulin, which acts primarily on relatively homogeneous organs such as the liver and muscle, leptin regulates a broadly distributed network of LRb-expressing neurones in the brain in order to orchestrate an array of neural processes that range from neuroendocrine and sympathetic nervous system function, to satiety, and to the perception of food reward. It is becoming increasingly clear that various facets of leptin action are contributed to by discrete populations of LRb neurones, and that the distributed network of $\mathrm{LRb}$ neurones collectively mediates the totality of leptin action.

\section{Leptin regulation of satiety}

Satiety is the perception of fullness that indicates that no further food ingestion is needed. The ARC and VMH are defined as 'satiety centres' because lesions of either promote hyperphagia and obesity (Elmquist et al. 2005, Morton et al. 2006). The contributions of the ARC to leptin-mediated satiety (e.g. via LRb/POMC and
$\mathrm{LRb} / \mathrm{NPY}$ ) is well characterized, as discussed above. $\mathrm{VMH} \mathrm{LRb}$ neurones also contribute to satiety via excitatory projections onto ARC POMC neurones (Pinto et al. 2004, Sternson et al. 2005). The density of these projections is dynamically regulated by leptin availability (i.e. fasting or fed states) demonstrating the exquisite sensitivity of the $\mathrm{VMH}$ to physiological changes. At least one subpopulation of VMH LRb neurones, those co-expressing the transcription factor SF-1, is activated by leptin and contribute to leptinmediated satiety (Dhillon et al. 2006).

Several areas of the brainstem, including the NTS and the area postrema, are also important for satiety (Elmquist et al. 2005, Grill 2006, Morton et al. 2006). The brainstem integrates numerous inputs from the gut [including those from vagal afferents and the anorexigenic gut peptides glucagon-like peptide-1 (GLP-1) and cholecystokinin (CCK)], as well as the hypothalamus, to modulate satiety (Grill 2006). Leptin acts synergistically with signals of gastric distension, GLP-1 and CCK to regulate the neurones of the NTS, and thus contribute to satiety (Morton et al. 2005, Williams et al. 2006, Huo et al. 2007). The NTS and other brainstem regions associated with satiety contain LRb neurones, and direct leptin action on brainstem LRb-expressing neurones as well as indirect leptin action via ARC LRb neurones that project to the brainstem may contribute to the satiety effects of leptin (Elmquist et al. 1998a, Grill et al. 2002, Ellacott et al. 2006a,b, Grill 2006, Leshan et al. 2006, Huo et al. 2007).

\section{Leptin regulation of the mesolimbic dopamine system}

In addition to satiety, the rewarding properties of food contribute to feeding (Kelley \& Berridge 2002, Figlewicz et al. 2006). For example, after ingestion of a meal you may feel satiated (full), but may go on to eat dessert because it seems appealing and tasty. Thus, the reward value of food induces ingestion beyond what is needed for satiety. Leptin regulates the reward value placed on food (as well as of other addictive substances, such as drugs of abuse) (Fulton et al. 2004, Carr 2006, Figlewicz et al. 2006). Some of the neural mechanisms by which leptin may control food reward are beginning to be elucidated via the investigation of the interaction of leptin with the mesolimbic dopamine (DA) system (Figlewicz 2003, Figlewicz et al. 2003, Fulton et al. 2006, Hommel et al. 2006). The core of the mesolimbic DA system lies in a set of DA neurones in the VTA that project forward to innervate the striatum (nucleus accumbens, caudate, putamen), amygdala and prefrontal cortex. It is by acting upon this system that drugs of abuse generally exert their reinforcing effects, and the activity of this system is clearly important to mediate 
the incentive salience of food and other natural rewards (Kelley \& Berridge 2002, Nestler 2005). The relationship between the DA system and energy homeostasis has been often described but is poorly understood. For example, side effects of antipsychotic drugs (that act in part as mixed DA antagonists) include weight gain and metabolic disease (Bergman \& Ader 2005).

While ARC LRb neurones do not project to the VTA, systemic leptin administration modulates food reward, suggesting a different locus for the regulation of DA signalling (Figlewicz et al. 2006). A number of groups have reported the presence of LRb-expressing VTA DA neurones and demonstrated the ability of leptin to alter the physiology of the DA system (Figlewicz 2003, Figlewicz et al. 2003, Fulton et al. 2006, Hommel et al. 2006). Thus, leptin may act directly upon VTA LRb neurones to regulate DA synthesis and release in the striatum and amygdala.

The lateral hypothalamic 'feeding' centre interacts extensively with the mesolimbic DA system to regulate motivation and reward, including food reward (Kelley \& Berridge 2002, DiLeone et al. 2003, Fulton et al. 2004). Furthermore, states of nutritional deficiency modulate rewarding intrahypothalamic self-stimulation (IHSS) in the perifornical area of the LHA (Fulton et al. 2004). LHA orexin neurones project to the VTA and regulate drug and food-associated reward signalling, and LHA melanin-concentrating hormone $(\mathrm{MCH})$ neurones interact with the striatum (DiLeone et al. 2003, Harris et al. 2005).

The LHA is another important locus of leptin action on the DA system. Leptin inhibits the activity of orexin neurones and reduces the expression of the LHA neuropeptide $\mathrm{MCH}$, as well as attenuating IHSS (Qu et al. 1996, Fulton et al. 2000, 2004, Yamanaka et al. 2003). Inhibition of OX and MCH signalling via their respective receptor antagonists inhibit food intake and modulate DA signalling in rodent models similar to leptin, and these pathways are thus potential drug targets for anxiety and weight loss. We have also identified a novel population of LRb-expressing neurones in the LHA that project to the VTA to regulate the mesolimbic DA system (our unpublished data). As in the ARC, these LHA LRb neurones are composed of multiple different subpopulations of neurones that are divergently regulated by leptin and other nutritional factors. Thus, leptin acts via multiple ARC-independent systems to control the VTA and the mesolimbic DA system at its inception in the VTA, and these sites of leptin action probably regulate the incentive salience of food.

\section{Summary}

The totality of leptin action neither reflects the output of a single intracellular signal nor that of a single (e.g.
ARC) neural circuit, but rather integrates multiple LRbstimulated signals acting in concert upon a widely distributed and heterogeneous array of LRb-expressing neurones. The spatial diversity along with the distinct complements of neurotransmitters employed by these myriad LRb-expressing neural populations suggests the divergent function of many subpopulations of $\mathrm{LRb}$ neurones even within the discrete LRb-expressing brain regions. It will be important to understanding the phenotype (neural inputs and outputs; neurotransmitters) of each distinct population of LRb-expressing neurones and the roles for the various LRb-mediated signals in each set of neurones in order to truly understand the mechanisms of leptin action. This information is likely to reveal not only novel information about leptin action, but also potential novel targets for the regulation of feeding and the treatment of obesity.

\section{Conflicts of interest}

The authors declare that they have no conflicts of interest.

\section{References}

Ahima, R.S., Prabakaran, D., Mantzoros, C.S., Qu, D., Lowell, B.B., Maratos-Flier, E. \& Flier, J.S. 1996. Role of leptin in the neuroendocrine response to fasting. Nature 382, 250-252.

Argetsinger, L.S., Kouadio, J.L., Steen, H., Stensballe, A., Jensen, O.N. \& Carter-Su, C. 2004. Autophosphorylation of JAK2 on tyrosines 221 and 570 regulates its activity. Mol Cell Biol 24, 4955-4967.

Balthasar, N., Coppari, R., McMinn, J., Liu, S.M., Lee, C.E., Tang, V., Kenny, C.D., McGovern, R.A., Chua, S.C. Jr, Elmquist, J.K. \& Lowell, B.B. 2004. Leptin receptor signaling in POMC neurons is required for normal body weight homeostasis. Neuron 42, 983-991.

Banks, A.S., Davis, S.M., Bates, S.H. \& Myers, M.G., Jr. 2000. Activation of downstream signals by the long form of the leptin receptor. J Biol Chem 275, 14563-14572.

Baskin, D.G., Schwartz, M.W., Seeley, R.J., Woods, S.C., Porte, D., Jr, Breininger, J.F., Jonak, Z., Schaefer, J., Krouse, M., Burghardt, C., Campfield, L.A., Burn, P. \& Kochan, J.P. 1999. Leptin receptor long-form splice-variant protein expression in neuron cell bodies of the brain and co-localization with neuropeptide Y mRNA in the arcuate nucleus. J Histochem Cytochem 47, 353-362.

Bates, S.H. \& Myers, M.G., Jr. 2003. The role of leptin receptor signaling in feeding and neuroendocrine function. Trends Endocrinol Metab 14, 447-452.

Bates, S.H., Stearns, W.H., Schubert, M., Tso, A.W.K., Wang, Y., Banks, A.S., Dundon, T.A., Lavery, H.J., Haq, A.K., Maratos-Flier, E., Neel, B.G., Schwartz, M.W. \& Myers, M.G., Jr. 2003. STAT3 signaling is required for leptin regulation of energy balance but not reproduction. Nature 421, 856-859. 
Bates, S.H., Dundon, T.A., Seifert, M., Carlson, M., MaratosFlier, E. \& Myers, M.G., Jr. 2004. LRb-STAT3 signaling is required for the neuroendocrine regulation of energy expenditure by leptin. Diabetes 53, 3067-3073.

Bates, S.H., Kulkarni, R.N., Seifert, M. \& Myers, M.G., Jr. 2005. Roles for leptin receptor/STAT3-dependent and -independent signals in the regulation of glucose homeostasis. Cell Metab 1, 169-178.

Bergman, R.N. \& Ader, M. 2005. Atypical antipsychotics and glucose homeostasis. J Clin Psychiatry 66, 504-514.

Bjorbaek, C., Elmquist, J.K., Frantz, J.D., Shoelson, S.E. \& Flier, J.S. 1998. Identification of SOCS-3 as a potential mediator of central leptin resistance. Mol Cell 1, 619-625.

Bjorbaek, C., Lavery, H.J., Bates, S.H., Olson, R.K., Davis, S.M., Flier, J.S. \& Myers, M.G., Jr. 2000. SOCS3 mediates feedback inhibition of the leptin receptor via Tyr985. J Biol Chem 275, 40649-40657.

Bjorbaek, C., Buchholz, R.M., Davis, S.M., Bates, S.H., Pierroz, D.D., Gu, H., Neel, B.G., Myers, M.G., Jr \& Flier, J.S. 2001. Divergent roles of SHP-2 in ERK activation by leptin receptors. J Biol Chem 276, 4747-4755.

Bjornholm, M., Munzberg, H., Leshan, R.L., Villanueva, E., Bates, S.H., Louis, G.W., Jones, J.C., Ishida-Takahashi, R., Bjorbaek, C. \& Myers, M.G., Jr. 2007. Mice lacking inhibitory leptin receptor signals are lean with normal endocrine function. J Clin Invest 117, 1354-1360.

Bodary, P.F., Westrick, R.J., Wickenheiser, K.J., Shen, Y. \& Eitzman, D.T. 2002. Effect of leptin on arterial thrombosis following vascular injury in mice. JAMA 287, 17061709.

Bodary, P.F., Shen, Y., Ohman, M., Bahrou, K.L., Vargas, F.B., Cudney, S.S., Wickenheiser, K.J., Myers, M.G., Jr \& Eitzman, D.T. 2007. Leptin regulates neointima formation after arterial injury through mechanisms independent of blood pressure and the leptin receptor/STAT3 signaling pathways involved in energy balance. Arterioscler Thromb Vasc Biol 27, 70-76.

Boston, B.A., Blaydon, K.M., Varnerin, J. \& Cone, R.D. 1997. Independent and additive effects of central POMC and leptin pathways on murine obesity. Science 278, 1641-1644.

Buettner, C., Pocai, A., Muse, E.D., Etgen, A.M., Myers, M.G., Jr \& Rossetti, L. 2006. Critical role of STAT3 in leptin's metabolic actions. Cell Metab 4, 49-60.

Butler, A.A. \& Cone, R.D. 2002. The melanocortin receptors: lessons from knockout models. Neuropeptides 36, 77-84.

Butler, A.A., Kesterson, R.A., Khong, K., Cullen, M.J., Pelleymounter, M.A., Dekoning, J., Baetscher, M. \& Cone, R.D. 2000. A unique metabolic syndrome causes obesity in the melanocortin-3 receptor-deficient mouse. Endocrinology 141, 3518-3521.

Carpenter, L.R., Farruggella, T.J., Symes, A., Karow, M.L. \& Yancopoulos, G. 1998. Enhancing leptin response by preventing $\mathrm{SH} 2$-containing phosphatase 2 interaction with $\mathrm{Ob}$ receptor. Proc Natl Acad Sci USA 95, 6061-6066.

Carpino, N., Kobayashi, R., Zang, H., Takahashi, Y., Jou, S.T., Feng, J., Nakajima, H. \& Ihle, J.N. 2002. Identification, cDNA cloning, and targeted deletion of p70, a novel, ubiquitously expressed $\mathrm{SH} 3$ domain-containing protein. Mol Cell Biol 22, 7491-7500.
Carr, K.D. 2006. Chronic food restriction: enhancing effects on drug reward and striatal cell signaling. Physiol Behav 91, 459-472.

Chen, A.S., Marsh, D.J., Trumbauer, M.E., Frazier, E.G., Guan, X.M., Yu, H., Rosenblum, C.I., Vongs, A., Feng, Y., Cao, L. et al. 2000. Inactivation of the mouse melanocortin3 receptor results in increased fat mass and reduced lean body mass. Nat Genet 26, 97-102.

Chua, S.C., Jr, Koutras, I.K., Han, L., Liu, S.M., Kay, J., Young, S.J., Chung, W.K. \& Leibel, R.L. 1997. Fine structure of the murine leptin receptor gene: splice site suppression is required to form two alternatively spliced transcripts. Genomics 45, 264-270.

Clark, J.T., Kalra, P.S. \& Kalra, S.P. 1985. Neuropeptide Y stimulates feeding but inhibits sexual behavior in rats. Endocrinology 117, 2435-2442.

Clement, K., Vaisse, C., Lahlou, N., Cabrol, S., Pelloux, V., Cassuto, D., Gourmelen, M., Dina, C., Chambaz, J., Lacorte, J.M., Basdevant, A., Bougneres, P., leBouc, Y., Froguel, P. \& Guy-Grand, B. 1998. A mutation in the human leptin receptor gene causes obesity and pituitary dysfunction. Nature 392, 398-401.

Cota, D., Proulx, K., Smith, K.A., Kozma, S.C., Thomas, G., Woods, S.C. \& Seeley, R.J. 2006. Hypothalamic mTOR signaling regulates food intake. Science 312, 927-930.

Couturier, C. \& Jockers, R. 2003. Activation of the leptin receptor by a ligand-induced conformational change of constitutive receptor dimers. J Biol Chem 270, 26604-26611.

Cowley, M.A., Smart, J.L., Rubinstein, M., Cerdan, M.G., Diano, S., Horvath, T.L., Cone, R.D. \& Low, M.J. 2001. Leptin activates anorexigenic POMC neurons through a neural network in the arcuate nucleus. Nature 411, 480-484.

Cui, Y., Huang, L., Elefteriou, F., Yang, G., Shelton, J.M., Giles, J.E., Oz, O.K., Pourbahrami, T., Lu, C.Y., Richardson, J.A., Karsenty, G. \& Li, C. 2004. Essential role of STAT3 in body weight and glucose homeostasis. Mol Cell Biol 24, 258-269.

Devos, R., Guisez, Y., Van der Heyden, J., White, D.W., Kalai, M., Fountoulakis, M. \& Plaetinck, G. 1997. Ligand-independent dimerization of the extracellular domain of the leptin receptor and determination of the stoichiometry of leptin binding. J Biol Chem 272, 18304-18310.

Dhillon, H., Zigman, J.M., Ye, C., Lee, C.E., McGovern, R.A., Tang, V., Kenny, C.D., Christiansen, L.M., White, R.D., Edelstein, E.A. et al. 2006. Leptin directly activates SF1 neurons in the $\mathrm{VMH}$, and this action by leptin is required for normal body-weight homeostasis. Neuron 49, 191-203.

DiLeone, R.J., Georgescu, D. \& Nestler, E.J. 2003. Lateral hypothalamic neuropeptides in reward and drug addiction. Life Sci 73, 759-768.

Dunn, S.L., Bjornholm, M., Bates, S.H., Chen, Z., Seifert, M. \& Myers, M.G., Jr. 2005. Feedback inhibition of leptin receptor/Jak2 signaling via Tyr1138 of the leptin receptor and suppressor of cytokine signaling 3. Mol Endocrinol 19, 925-938.

Ellacott, K.L. \& Cone, R.D. 2006. The role of the central melanocortin system in the regulation of food intake and energy homeostasis: lessons from mouse models. Philos Trans R Soc Lond B Biol Sci 361, 1265-1274. 
Ellacott, K.L., Halatchev, I.G. \& Cone, R.D. 2006a. Characterization of leptin-responsive neurons in the caudal brainstem. Endocrinology 147, 3190-3195.

Ellacott, K.L., Halatchev, I.G. \& Cone, R.D. 2006b. Interactions between gut peptides and the central melanocortin system in the regulation of energy homeostasis. Peptides 27, 340-349.

Elmquist, J.K., Bjorbaek, C., Ahima, R.S., Flier, J.S. \& Saper, C.B. 1998a. Distributions of leptin receptor mRNA isoforms in the rat brain. J Comp Neurol 395, 535-547.

Elmquist, J.K., Maratos-Flier, E., Saper, C.B. \& Flier, J.S. 1998b. Unraveling the central nervous system pathways underlying responses to leptin. Nat Neurosci 1, 445-449.

Elmquist, J.K., Coppari, R., Balthasar, N., Ichinose, M. \& Lowell, B.B. 2005. Identifying hypothalamic pathways controlling food intake, body weight, and glucose homeostasis. J Comp Neurol 493, 63-71.

Erickson, J.C., Hollopeter, G. \& Palmiter, R.D. 1996. Attenuation of the obesity syndrome of ob/ob mice by the loss of neuropeptide Y. Science 274, 1704-1707.

Feener, E.P., Rosario, F., Dunn, S.L., Stancheva, Z. \& Myers, M.G., Jr. 2004. Tyrosine phosphorylation of Jak2 in the JH2 domain inhibits cytokine signaling. Mol Cell Biol 24, 49684978.

Feng, G.S. 1999. Shp-2 tyrosine phosphatase: signaling one cell or many. Exp Cell Res 253, 47-54.

Feng, J., Witthuhn, B.A., Matsuda, T., Kohlhuber, F., Kerr, I.M. \& Ihle, J.N. 1997. Activation of Jak2 catalytic activity requires phosphorylation of $\mathrm{Y}^{1007}$ in the kinase activation loop. Mol Cell Biol 17, 2497-2501.

Figlewicz, D.P. 2003. Adiposity signals and food reward: expanding the CNS roles of insulin and leptin. Am J Physiol Regul Integr Comp Physiol 284, R882-R892.

Figlewicz, D.P., Evans, S.B., Murphy, J., Hoen, M. \& Baskin, D.G. 2003. Expression of receptors for insulin and leptin in the ventral tegmental area/substantia nigra (VTA/SN) of the rat. Brain Res 964, 107-115.

Figlewicz, D.P., Naleid, A.M. \& Sipols, A.J. 2006. Modulation of food reward by adiposity signals. Physiol Behav 91, 473478.

Friedman, J.M. \& Halaas, J.L. 1998. Leptin and the regulation of body weight in mammals. Nature 395, 763-770.

Fulton, S., Woodside, B. \& Shizgal, P. 2000. Modulation of brain reward circuitry by leptin. Science 287, 125-128.

Fulton, S., Richard, D., Woodside, B. \& Shizgal, P. 2004. Food restriction and leptin impact brain reward circuitry in lean and obese Zucker rats. Behav Brain Res 155, 319-329.

Fulton, S., Pissios, P., Manchon, R.P., Stiles, L., Frank, L., Pothos, E.N., Maratos-Flier, E. \& Flier, J.S. 2006. Leptin regulation of the mesoaccumbens dopamine pathway. Neuron 51, 811-822.

Funakoshi-Tago, M., Pelletier, S., Matsuda, T., Parganas, E. \& Ihle, J.N. 2006. Receptor specific downregulation of cytokine signaling by autophosphorylation in the FERM domain of Jak2. EMBO J 25, 4763-4772.

Ge, H., Huang, L., Pourbahrami, T. \& Li, C. 2002. Generation of soluble leptin receptor by ectodomain shedding of membrane-spanning receptors in vitro and in vivo. $J$ Biol Chem 277, 45898-45903.
Gong, Y., Ishida-Takahashi, R., Villanueva, E.C., Fingar, D.C., Münzberg, H. \& Myers, M.G., Jr. 2007. The long form of the leptin receptor regulates STAT5 and ribosomal protein S6 via alternate mechanisms. J Biol Chem 282, 3101931027.

Grill, H.J. 2006. Distributed neural control of energy balance: contributions from hindbrain and hypothalamus. Obesity (Silver Spring) 14(Suppl. 5), 216S-221S.

Grill, H.J., Schwartz, M.W., Kaplan, J.M., Foxhall, J.S., Breininger, J. \& Baskin, D.G. 2002. Evidence that the caudal brainstem is a target for the inhibitory effect of leptin on food intake. Endocrinology 143, 239-246.

Haan, S., Hemmann, U., Hassiepen, U., Schaper, F., SchneiderMergener, J., Wollmer, A., Heinrich, P.C. \& Grotzinger, J. 1999. Characterization and binding specificity of the monomeric STAT3-SH2 domain. J Biol Chem 274, 13421348.

Harris, G.C., Wimmer, M. \& Aston-Jones, G. 2005. A role for lateral hypothalamic orexin neurons in reward seeking. Nature 437, 556-559.

Hekerman, P., Zeidler, J., Bamberg-Lemper, S., Knobelspies, H., Lavens, D., Tavernier, J., Joost, H.G. \& Becker, W. 2005. Pleiotropy of leptin receptor signalling is defined by distinct roles of the intracellular tyrosines. FEBS $J$ 272, 109-119.

Hommel, J.D., Trinko, R., Sears, R.M., Georgescu, D., Liu, Z.W., Gao, X.B., Thurmon, J.J., Marinelli, M. \& DiLeone, R.J. 2006. Leptin receptor signaling in midbrain dopamine neurons regulates feeding. Neuron 51, 801-810.

Howard, J.K., Cave, B.J., Oksanen, L.J., Tzameli, I., Bjorbaek, C. \& Flier, J.S. 2004. Enhanced leptin sensitivity and attenuation of diet-induced obesity in mice with haploinsufficiency of Socs3. Nat Med 10, 734-738.

Huo, L., Maeng, L., Bjorbaek, C. \& Grill, H.J. 2007. Leptin and the control of food intake: neurons in the nucleus of the solitary tract are activated by both gastric distension and leptin. Endocrinology 148, 2189-2197.

Huszar, D., Lynch, C.A., Fairchild-Huntress, V., Dunmore, J.H., Fang, Q., Berkemeier, L.R., Gu, W., Kesterson, R.A., Boston, B.A., Cone, R.D., Smith, F.J., Campfield, L.A., Burn, P. \& Lee, F. 1997. Targeted disruption of the melanocortin4 receptor results in obesity in mice. Cell 88, 131-141.

Ihle, J.N. \& Kerr, I.M. 1995. Jaks and Stats in signaling by the cytokine receptor superfamily. Trends Genet 11, 69-74.

Ishida-Takahashi, R., Rosario, F., Gong, Y., Kopp, K., Stancheva, Z., Chen, X., Feener, E.P. \& Myers, M.G., Jr. 2006. Phosphorylation of Jak2 on Ser(523) inhibits Jak2-dependent leptin receptor signaling. Mol Cell Biol 26, 4063-4073.

Kaelin, C.B., Gong, L., Xu, A.W., Yao, F., Hockman, K., Morton, G.J., Schwartz, M.W., Barsh, G.S. \& MacKenzie, R.G. 2006. Signal transducer and activator of transcription (stat) binding sites but not stat 3 are required for fastinginduced transcription of agouti-related protein messenger ribonucleic acid. Mol Endocrinol 20, 2591-2602.

Keilhack, H., David, F.S., McGregor, M., Cantley, L.C. \& Neel, B.G. 2005. Diverse biochemical properties of Shp2 mutants. Implications for disease phenotypes. $\mathrm{J} \mathrm{Biol} \mathrm{Chem}$ 280, 30984-30993. 
Kelley, A.E. \& Berridge, K.C. 2002. The neuroscience of natural rewards: relevance to addictive drugs. J Neurosci 22, 3306-3311.

Kloek, C., Haq, A.K., Dunn, S.L., Lavery, H.J., Banks, A.S. \& Myers, M.G., Jr. 2002. Regulation of Jak kinases by intracellular leptin receptor sequences. J Biol Chem 277, 4154741555.

Koch, C.A., Anderson, D.J., Moran, M.F., Ellis, C.A. \& Pawson, T. 1991. SH2 and SH3 domains: elements that control interactions of cytoplasmic signaling proteins. Science 252, 668-674.

Kurzer, J.H., Argetsinger, L.S., Zhou, Y.J., Kouadio, J.L., O'Shea, J.J. \& Carter-Su, C. 2004. Tyrosine 813 is a site of JAK2 autophosphorylation critical for activation of JAK2 by SH2-B beta. Mol Cell Biol 24, 4557-4570.

Leshan, R.L., Bjornholm, M., Munzberg, H. \& Myers, M.G., Jr. 2006. Leptin receptor signaling and action in the central nervous system. Obesity (Silver Spring) 14(Suppl. 5), 208S212S.

Li, C. \& Friedman, J.M. 1999. Leptin receptor activation of SH2 domain containing protein tyrosine phosphatase 2 modulates $\mathrm{Ob}$ receptor signal transduction. Proc Natl Acad Sci USA 96, 9677-9682.

Lord, G.M., Matarese, G., Howard, J.K., Baker, R.J., Bloom, S.R. \& Lechler, R.I. 1998. Leptin modulates the T-cell immune response and reverses starvation-induced immunosuppression. Nature 394, 897-901.

MacNeil, D.J., Howard, A.D., Guan, X., Fong, T.M., Nargund, R.P., Bednarek, M.A., Goulet, M.T., Weinberg, D.H., Strack, A.M., Marsh, D.J. et al. 2002. The role of melanocortins in body weight regulation: opportunities for the treatment of obesity. Eur J Pharmacol 450, 93-109.

Marsh, D.J., Hollopeter, G., Huszar, D., Laufer, R., Yagaloff, K.A., Fisher, S.L., Burn, P. \& Palmiter, R.D. 1999. Response of melanocortin-4 receptor-deficient mice to anorectic and orexigenic peptides. Nat Genet 21, 119-122.

Matsuda, T., Feng, J., Witthuhn, B.A., Sekine, Y. \& Ihle, J.N. 2004. Determination of the transphosphorylation sites of Jak2 kinase. Biochem Biophys Res Commun 325, 586594.

Minokoshi, Y., Alquier, T., Furukawa, N., Kim, Y.B., Lee, A., Xue, B., Mu, J., Foufelle, F., Ferre, P., Birnbaum, M.J., Stuck, B.J. \& Kahn, B.B. 2004. AMP-kinase regulates food intake by responding to hormonal and nutrient signals in the hypothalamus. Nature 428, 569-574.

Montague, C.T., Farooqi, I.S., Whitehead, J.P., Soos, M.S., Rau, H., Wareham, N.J., Sewter, C.P., Digby, J.E., Mohammed, S.N., Hurst, J.A., Cheetham, C.H., Early, A.R., Barnett, A.H., Prins, J.B. \& O’Rahilly, S. 1997. Congenital leptin deficiency is associated with severe early onset obesity in humans. Nature 387, 903-908.

Mori, H., Hanada, R., Hanada, T., Aki, D., Mashima, R., Nishinakamura, H., Torisu, T., Chien, K.R., Yasukawa, H. \& Yoshimura, A. 2004. Socs3 deficiency in the brain elevates leptin sensitivity and confers resistance to diet-induced obesity. Nat Med 10, 739-743.

Morton, G.J., Niswender, K.D., Rhodes, C.J., Myers, M.G., Jr, Blevins, J.T., Baskin, D.G. \& Schwartz, M.W. 2003. Arcuate nucleus-specific leptin receptor gene therapy attenuates the obesity phenotype of Koletsky (fak/fak) rats. Endocrinology 144, 2016-2024.

Morton, G.J., Blevins, J.E., Williams, D.L., Niswender, K.D., Gelling, R.W., Rhodes, C.J., Baskin, D.G. \& Schwartz, M.W. 2005. Leptin action in the forebrain regulates the hindbrain response to satiety signals. J Clin Invest 115, 703-710.

Morton, G.J., Cummings, D.E., Baskin, D.G., Barsh, G.S. \& Schwartz, M.W. 2006. Central nervous system control of food intake and body weight. Nature 443, 289-295.

Munzberg, H., Huo, L., Nillni, E.A., Hollenberg, A.N. \& Bjorbaek, C. 2003. Role of signal transducer and activator of transcription 3 in regulation of hypothalamic proopiomelanocortin gene expression by leptin. Endocrinology 144, 2121-2131.

Munzberg, H., Jobst, E.E., Bates, S.H., Jones, J., Villanueva, E., Leshan, R., Bjornholm, M., Elmquist, J., Sleeman, M., Cowley, M.A. \& Myers, M.G., Jr. 2007. Appropriate inhibition of orexigenic hypothalamic arcuate nucleus neurons independently of leptin receptor/STAT3 signaling. J Neurosci 27, 69-74.

Nestler, E.J. 2005. Is there a common molecular pathway for addiction? Nat Neurosci 8, 1445-1449.

Niswender, K.D., Morton, G.J., Stearns, W.H., Rhodes, C.J., Myers, M.G., Jr \& Schwartz, M.W. 2001. Intracellular signalling key enzyme in leptin-induced anorexia. Nature 413, 794-795.

Ollmann, M.M., Wilson, B.D., Yang, Y.K., Kerns, J.A., Chen, Y., Gantz, I. \& Barsh, G.S. 1997. Antagonism of central melanocortin receptors in vitro and in vivo by agouti-related protein. Science 278, 135-138.

Pinto, S., Roseberry, A.G., Liu, H., Diano, S., Shanabrough, M., Cai, X., Friedman, J.M. \& Horvath, T.L. 2004. Rapid rewiring of arcuate nucleus feeding circuits by leptin. Science 304, 110-115.

Plum, L., Ma, X., Hampel, B., Balthasar, N., Coppari, R., Munzberg, H., Shanabrough, M., Burdakov, D., Rother, E., Janoschek, R. et al. 2006. Enhanced PIP(3) signaling in POMC neurons causes K(ATP) channel activation and leads to diet-sensitive obesity. J Clin Invest 116, 1886-1901.

Qu, D., Ludwig, D.S., Gammeltoft, S., Piper, M., Pelleymounter, M.A., Cullen, M.J., Mathes, W.F., Przypek, J., Kanarek, R. \& Maratos-Flier, E. 1996. A role for melaninconcentrating hormone in the central regulation of feeding behavior. Nature 380, 243-247.

Sasaki, A., Yasukawa, H., Shouda, T., Kitamura, T., Dikic, I. \& Yoshimura, A. 2000. CIS3/SOCS3 suppresses erythropoietin signaling by binding the EPO receptor and JAK2. J Biol Chem 275, 29338-29347.

Smith, M.A., Hisadome, K., Al Qassab, H., Heffron, H., Withers, D.J. \& Ashford, M.L. 2007. Melanocortins and agouti-related protein modulate the excitability of two arcuate nucleus neuron populations by alteration of resting potassium conductances. J Physiol 578(Pt 2), 425-438.

Songyang, Z., Shoelson, S.E., Chaudhuri, M., Gish, G.D., Pawson, T., Haser, W.G., King, F., Roberts, T., Ratnofsky, S., Lechleider, R.J. et al. 1993. SH2 domains recognize specific phosphopeptide sequences. Cell 72, 767-778.

Ste, M.L., Miura, G.I., Marsh, D.J., Yagaloff, K. \& Palmiter, R.D. 2000. A metabolic defect promotes obesity in mice 
lacking melanocortin-4 receptors. Proc Natl Acad Sci USA 97, 12339-12344.

Sternson, S.M., Shepherd, G.M. \& Friedman, J.M. 2005. Topographic mapping of $\mathrm{VMH} \rightarrow$ arcuate nucleus microcircuits and their reorganization by fasting. Nat Neurosci 8, 1356-1363.

Taga, T. \& Kishimoto, T. 1997. gp130 and the interleukin-6 family of cytokines. Annu Rev Immunol 15, 797-819.

Taniguchi, T. 1995. Cytokine signaling through nonreceptor protein tyrosine kinases. Science 268, 251-255.

Tartaglia, L.A. 1997. The leptin receptor. J Biol Chem 272, 6093-6096.

White, D.W., Kuropatwinski, K.K., Devos, R., Baumann, H. \& Tartaglia, L.A. 1997. Leptin receptor (OB-R) signaling. J Biol Chem 272, 4065-4071.

Williams, D.L., Baskin, D.G. \& Schwartz, M.W. 2006. Leptin regulation of the anorexic response to glucagon-like peptide1 receptor stimulation. Diabetes 55, 3387-3393.
Xu, A.W., Kaelin, C.B., Takeda, K., Akira, S., Schwartz, M.W. \& Barsh, G.S. 2005. PI3K integrates the action of insulin and leptin on hypothalamic neurons. J Clin Invest 115, 951-958.

Xu, A.W., Ste-Marie, L., Kaelin, C.B. \& Barsh, G.S. 2006. Inactivation of Stat 3 in Pomc neurons causes decreased Pomc expression, mild obesity and defects in compensatory refeeding. Endocrinology 148, 72-80.

Yamanaka, A., Beuckmann, C.T., Willie, J.T., Hara, J., Tsujino, N., Mieda, M., Tominaga, M., Yagami, K., Sugiyama, F., Goto, K., Yanagisawa, M. \& Sakurai, T. 2003. Hypothalamic orexin neurons regulate arousal according to energy balance in mice. Neuron 38, 701-713.

Zhang, E.E., Chapeau, E., Hagihara, K. \& Feng, G.S. 2004. Neuronal Shp2 tyrosine phosphatase controls energy balance and metabolism. Proc Natl Acad Sci USA 101, 1606416069. 